\title{
A narrativa organizacional para a promoção do engajamento
}

Larissa Conceição dos Santos

\section{Resumo}

Este trabalho analisa o papel das narrativas organizacionais para a promoção do engajamento.

A investigação tem como foco a função argumentativa e a capacidade mobilizadora das narrativas produzidas pelas organizações e destinadas a seus públicos de interesse. Adotase uma perspectiva interpretativa visando à compreensão das narrativas organizacionais, sua capacidade de argumentação e de mobilização para a ação, tendo como fundamento teórico os estudos sobre a narratologia, pela perspectiva da narrativa das organizações, a teoria do texto, a teoria da ação e a teoria dos atos de linguagem. Como objeto de estudo são analisados os materiais promocionais desenvolvidos pela Fondation Cité Internationale Universitaire de Paris (CIUP) destinados a obter 0 apoio mecenas. Para tanto, a pesquisa apoia-se nas metodologias de análise de discurso e análise de conteúdo.

\section{Palavras-chave}

Comunicação organizacional. Narrativa. Organizações.

\section{Larissa Conceição dos Santos}

| larissa.conceicao_dos_santos@celsa.paris-sorbonne.fr Doutoranda em Sciences de l'Information et de la Communication, CELSA, Université Paris-Sorbonne (Paris IV). Pesquisadora no Laboratoire Gripic (CELSA, Paris IV). Bolsista Capes de Doutorado Pleno no Exterior (BEX n.1195-12-3).

\section{Introdução}

Diversas são as perspectivas teóricas que se propõem a analisar a comunicação produzida pelas organizações ${ }^{1}$ e no interior delas, originando os campos de estudo da comunicação empresarial, comunicação corporativa ou comunicação organizacional, termo que será adotado ao longo deste trabalho.

As empresas comunicam-se e interagem com os diversos públicos por meio de diferentes processos comunicacionais, dentre os quais se destaca 0 emprego de narrativas como uma vertente do estudo da comunicação nas organizações. Tratase de uma abordagem narrativa da comunicação organizacional, uma linha de pesquisa que ganha visibilidade e diferencia-se por observar as empresas enquanto produtoras de narrativas.

Diante da crise das metanarrativas (LYOTARD, 1979), a sociedade encontra-se em uma constante busca de referências, de sentidos, de valores, de explicações e justificações. Este cenário propicia a formação e circulação 
de novas narrativas legitimadoras, como as produzidas pelas organizações. Essas narrativas contam, mostram, explicam, mas também podem suscitar uma ação ou mudança, ao estimularem e mobilizarem seus receptores.

Assim, pretende-se analisar a função mobilizadora das narrativas organizacionais, salientando-se sua força enquanto portadoras de uma autoridade intrínseca e algumas vezes moralizante. Esta força interpeladora (BÜHLER; HABERMACHER, 1988) da narrativa vai muito além do texto, do discurso e da legitimidade do autor/narrador. Ela nos convida a investigar a capacidade argumentativa das narrativas a partir de sua função de comunicação.

A fim de observar a produção de narrativas e seu caráter mobilizador, especialmente para a promoção do engajamento pessoal a uma causa ou ação, realizou-se um estudo de caso tendo como objeto os relatos elaborados pela Cité Internationale Universitaire de Paris (CIUP) e difundidos por meio defolders de divulgação de seus projetos visando obter apoio mecenas. As produções elaboradas pela CIUP servem de exemplo para compreendermos como as organizações utilizam a forma narrativa para motivar os indivíduos a agir ou se engajarem em favor de uma causa ou de um projeto.

0 estudo possui caráter exploratório e interpretativo. Fundamenta-se na hermenêutica com o objetivo de compreender o fenômeno da construção de narrativas organizacionais, e nas teorias da ação (PARSONS, 1978), do texto (BARTHES, 1974) e dos atos de linguagem (AUSTIN, 1962; SEARLE, 1969) para entender as formas de mobilização e promoção do engajamento suscitadas pelos textos narrativos.

\section{A comunicação organizacional observada sob o prisma narrativo}

Oriunda do diálogo fecundo entre os campos da comunicação, os estudos organizacionais - perspectiva narrativa das organizações e os estudos literários - teoria narrativa e narratologia -, concebe-se a comunicação organizacional como um processo de produção narrativa que objetiva legitimar a organização e propor um novo sentido à atividade humana.

A perspectiva narrativa aplicada a contexto organizacional pode ser observada nas pesquisas de ciências da gestão, conforme destacam Giroux e Marroquin (2005). Ao analisar os estudos sobre a abordagem narrativa das organizações, as autoras identificaram cinco perspectivas: 1) funcionalista, baseada na instrumentalização da narrativa como apoio ao sistema de gestão; 2) interpretativa, em que a narração é utilizada para partilhar representações, significações e mesmo refletir a 
cultura organizacional; 3) processual, observa o processo de construção da realidade apoiado no uso de narrativas; 4) crítica, as narrativas são utilizadas para gerar a submissão, mas são igualmente canais de denúncia e de resistência; 5) pós-moderna, analisa as narrativas dominantes e a construção das organizações a partir dos discursos hegemônicos.

A abordagem narrativa foi introduzida aos estudos comunicacionais na década de 1990, resultante de um processo de reinterpretação das organizações que fez emergir uma série de teorias alternativas. Uma delas, a chamada teoria narrativa pósmoderna, tem por base a condição pós-moderna preconizada por Lyotard (1979), em que a história ocupa o papel principal e é entendida como metanarrativa (SCROFERNEKER, 2006).

As narrativas produzidas pelas organizações compreendem "[...] um conjunto de narrações que propõem um sentido, uma significação e uma finalidade, na qual a empresa é contada ao contar o mundo" (D'ALMEIDA, 2006, p. 147). Conforme a proposição de D'Almeida (2001), as narrativas organizacionais ${ }^{2}$ podem ser classificadas em dois tipos: narrativas da casa, baseadas nos valores e identidades organizacionais como forma de coligar o público interno; e as narrativas de engajamento, relatos que visam legitimar as ações organizacionais recorrendo a valores universais.
Face à crise das metanarrativas, explicativas e hegemônicas, proclamadas por Lyotard (1979) como figuras da pós-modernidade, novas narrativas universais e totalizadoras emergem na sociedade tendo por protagonistas as organizações. As narrativas organizacionais se autolegitimam, assim, como vozes alternativas: seu poder e autoridade são proclamados, o status conferido à organização é autorizado pelo Estado ou ainda negociado com ele, mas, sobretudo, aceito pelos indivíduos.

Os atores econômicos constroem suas narrativas para dar visibilidade a suas ações. A construção e difusão das narrativas organizacionais surgem, portanto, em resposta à urgência imposta pelo capitalismo, em que as empresas configuram e reconfiguram seus relatos, pressionadas por exigências instantâneas e decisões de curto prazo (D'ALMEIDA, 2004).

A organização é, assim, legitimada e produtora de legitimação. Sua legitimação é buscada junto à sociedade através dos relatos que ela propaga. Isto é, essas narrativas são portadoras de um discurso de legitimação, que busca instituir os ideais organizacionais, tendências de consumo ou de cultura e comportamento de maneira implícita (SANTOS, 2012).

Nesse sentido, observa-se não apenas a capacidade influenciadora, mas também 
mobilizadora inerente às narrativas

organizacionais. A narrativa é, então, entendida neste trabalho como um fenômeno de comunicação, e como tal será analisada por meio do estudo das narrativas veiculadas em dois folders institucionais produzidos pela CIUP com vistas a conquistar 0 engajamento dos mecenas.

\section{A mobilização instigada pela narrativa}

0 interesse do estudo sobre 0 caráter mobilizador das narrativas, parte da hipótese de que as organizações constroem seus relatos visando muito mais que simplesmente informar ou comunicar, mas principalmente obter 0 engajamento dos diferentes públicos para uma determinada causa.

Nesta pesquisa, a produção de narrativas organizacionais é compreendida como um processo comunicacional que mobiliza para uma ação. A proposta é construída tendo como base a teoria da ação (PARSONS, 1937, 1978), a teoria dos atos de linguagem (AUSTIN, 1962; SEARLE, 1969) e a teoria do texto (BARTHES, 1974).

Segundo a teoria da ação social preconizada por Parsons (1937), as ações são influenciadas por orientações que recebemos ao longo da vida, desde a socialização da criança até os processos de cumprimento de regras nas empresas, por exemplo. A ação deriva da conformidade pessoal às normas coletivas, incorporadas à personalidade dos indivíduos e institucionalizadas pela estrutura social.
Esta perspectiva nos conduz à reflexão sobre a maneira como somos motivados a agir. Faz-se necessário considerar a liberdade de escolha e a vontade pessoal implicadas na decisão de agir, mas também reconhecer a intencionalidade existente, tal como ela é concebida por Von Wright (1963), compreendida do no ato em si.

As narrativas organizacionais são consideradas processos comunicacionais que objetivam mobilizar os indivíduos para uma ação (de consumo, de compra, adoção de uma prática etc.), a engajar-se em favor de uma organização, apoiando suas atividades e tornando-se cliente, no caso do público externo, ou trabalhando para o cumprimento de sua missão e objetivos, no caso do público interno (SANTOS, 2012).

A fim de compreender como as narrativas escritas podem mobilizar para uma ação, busca-se estudar, neste trabalho, as implicações do texto, enquanto construção enunciativa e discursiva, de maneira a entender como a leitura de um relato pode instigar os indivíduos a agir, a ponto de voluntariamente engajar-se em uma causa.

Barthes (1974, p. 3) considera o texto "[...] um fragmento de linguagem situado ele mesmo em uma perspectiva de linguagem". 0 autor defende que 0 texto é uma "produtividade", isto é, está constantemente em produção, trabalha a língua sem cessar, em um processo no qual participam 0 autor (produtor do texto) e 0 leitor. 0 estabelecimento da produtividade se processa 
no jogo comunicacional estabelecido entre estes dois participantes: 0 autor, de seu lado, joga com a construção textual, enquanto o leitor joga com 0 repertório que possui para interpretar o texto.

Para Ricoeur (1986, p. 137), o texto pode ser definido como "[...] um discurso fixado pela escrita". Esta definição se aproxima do conceito de discurso que aqui retomamos em seu caráter narrativo, através da construção de narrativas organizacionais. Trata-se de um discurso que toma a forma narrativa, em que as ações, os feitos e os acontecimentos nele são relatados.

Com relação à organização textual, a narrativa pode ser definida como um texto que tem por gênero discursivo o narrativo. Ao abordar as narrativas em sua forma textual, observa-se 0 discurso materializado através da escrita. No presente estudo, a análise textual das narrativas tem como base a pesquisa interpretativa, tendo a compreensão das estratégias discursivas e argumentativas no centro da investigação.

0 diálogo entre a teoria da ação, exposto anteriormente, e a teoria do texto possibilita observar a relação complementar estabelecida entre essas duas abordagens, em que o texto é portador de intenções, de valores e de uma visão, os quais são interpretados pelo leitor que, por sua vez, toma a decisão de agir (ou não). A passagem do texto para a ação se faz, portanto, através da linguagem. Tal raciocínio nos conduz, deste modo, ao estudo da linguagem a partir do ponto onde as teorias (da ação e do texto) se encontram: sob a luz da teoria dos atos de linguagem.

Austin (1965) sugere que dizer é transmitir (comunicar) informações, mas é também e, sobretudo, uma forma de agir sobre $\mathrm{o}$ interlocutor e sobre o meio. Através da teoria dos atos de linguagem (ou atos da fala), 0 autor afirma que a linguagem não serve apenas para descrever, mas também para incitar uma ação. Por meio da análise dos atos performativos e constatativos, conclui que todos os enunciados são performativos, isto é, denotam uma ação. A proposta de Austin (1965) é retomada e aprofundada por Searle (1969), o qual enfatiza o papel da linguagem para além da descrição, mas como um meio de agir sobre a realidade.

Entende-se, assim, a narração como um ato de linguagem que promove ações (e reações), reflexões, e mesmo a mudança e 0 engajamento daqueles a quem se direciona. A partir do exposto, busca-se estudar a mobilização estimulada pelas narrativas construídas pela CIUP com vistas a promover o mecenato e que servem de exemplo para a compreensão do processo narrativo desenvolvido pelas organizações no intuito de mobilizar e conquistar o engajamento dos diferentes públicos em favor de sua causa.

\section{Panorama analítico e metodologia do estudo}

A Cité Internationale Universitaire de Paris é uma fundação criada em 1925 e reconhecida 
como de utilidade pública, constituindo-se como um espaço de alojamento, intercâmbio cultural, artístico e científico aos estudantes e investigadores de todo o mundo.

Esse tipo singular de organização chama a atenção para o papel destinado às narrativas e para a importância do engajamento para a sobrevivência das fundações. Assim, foram analisadas as narrativas produzidas pela CIUP à ocasião de uma campanha que objetivava conquistar apoio em prol dos projetos desenvolvidos pela fundação. ${ }^{3}$ Considerando o engajamento mecenas visado por esse tipo de comunicação, a pesquisa tem por foco os textos construídos pela CIUP, analisados enquanto narrativas e difundidos por meio de folders dirigidos aos potenciais mecenas (empresas e pessoas físicas) no intuito de obter doações financeiras.

Desse modo, focaliza-se a análise em dois folders institucionais elaborados pela Fundação CIUP para a promoção do mecenato e obtenção de doações monetárias. Os folders foram observados apenas em seus elementos textuais, uma vez que o objetivo principal deste trabalho consiste em realizar uma análise discursiva da campanha visando compreender como a instituição se descreve, se autolegitima e organiza sua construção narrativa a fim de conquistar 0 engajamento do público em prol de sua causa.
Realiza-se uma análise hermenêutica visando à identificação das estratégias gerais de construção das narrativas, as grandes áreas temáticas abordadas nos relatos produzidos pela CIUP e a maneira como são apresentados. Ao optar-se pela metodologia hermenêutica primamos pela interpretação e compreensão dos fenômenos, para tanto, toma-se por base a tríade hermenêutica proposta por Hernadi (1987 apud CZARNIAWSKA, 1998, p. 16). 0 autor sugere três caminhos para a leitura e interpretação dos textos: a explicação, a explanação e a exploração. Este trabalho concentra-se apenas nas duas primeiras etapas sugeridas pelo autor.

A análise apoiada na explicação remete à leitura buscando a compreensão. Neste caso, o leitor posiciona-se discursivamente como inferior ao texto e apreende-o através de uma leitura ingênua. Já por meio da explanação, o leitor posiciona-se acima do texto, questionando-se como ele é construído e quais são as diferentes maneiras de expressar 0 que 0 autor pretende dizer.

A análise hermenêutica possibilitou a identificação de duas estratégias principais nos relatos elaborados pela CIUP: uma estratégia narrativa e outra editorial. A estratégia narrativa diz respeito às escolhas discursivas e argumentativas desenvolvidas com o intuito de apresentar a CIUP e seus projetos. A estratégia editorial consiste na utilização do recurso 
gráfico "negrito" em certas palavras, expressões e frases destacadas nos materiais de divulgação da Fundação. Tais constatações nos indicam uma possível construção narrativa com vistas ao engajamento e à mobilização dos públicos .

Como forma de explorar as estratégias identificadas, bem como de compreender as escolhas discursivas e editoriais adotadas nos relatos institucionais, foram empregados os métodos de análise de discurso (FAIRCLOUGH, 1992) e análise de conteúdo (BONVILLE, 2006). A análise de conteúdo possibilitou a identificação da emergência de conceitos-chave, áreas e expressões mencionadas nas narrativas, que denotam os elementos estratégicos pelos quais a CIUP busca enfatizar em seu discurso. Através da análise de discurso observou-se a construção discursiva adotada pela Fundação, no contexto particular de promoção do mecenato.

\section{Estratégia editorial: realçando os elementos-chave}

0 processo de construção textual, para além de uma simples preocupação com relação à estética, simboliza uma estratégia de enunciação editorial (SOUCHIER, 1998). A análise dos folders da CIUP possibilitou observar que certas palavras e expressões são destacadas por meio do recurso textual "negrito". Esse tratamento tipográfico é uma estratégia adotada pelo enunciador para conferir maior visibilidade aos elementos do texto, destaque às palavras-chave, às ideias centrais e às expressões portadoras de um valor particular.

A fim de explorar essa tática de formatação do texto e identificar quais são os elementos lexicais que a CIUP busca destacar em suas narrativas de promoção institucional e de incentivo ao mecenato, emprega-se a análise de conteúdo adaptada aos estudos comunicacionais (BONVILLE, 2006). Em um primeiro momento foram selecionadas todas as palavras e expressões destacadas (com 0 recurso tipográfico negrito) nos textos dos folders promocionais da CIUP. Tais elementos foram classificados e agrupados de acordo com a categoria lexical mobilizada.

A partir da análise de dois folders produzidos pela CIUP e destinados aos potenciais mecenas particulares e privados (empresas, outras associações), ressaltam-se cinco categorias que remetem às escolhas lexicais adotadas pela fundação e intencionalmente destacadas em suas narrativas: a) palavras denotando Valores; b) palavras identificando os Beneficiários; c) palavras e expressões remetendo aos Objetivos e às Contribuições à sociedade; d) palavras e expressões Qualificativas; e) palavras e expressões de incitação/relativas ao Engajamento. 
A Figura 1 resume, de maneira ilustrativa, as palavras e expressões destacadas graficamente no folder destinado aos potenciais mecenas/doadores particulares. ${ }^{4}$ Os elementos foram agrupados tendo por base as cinco categorias identificadas e a frequência de ocorrência da expressão, assinalada pelo do número entre parêntesis.

A categoria Valores remete às palavras e expressões denotando os princípios e ideais que a instituição escolheu evidenciar, os quais afirma defender. Observam-se palavras remetendo a valores sociais, humanitários, e mesmo universalistas, como, por exemplo: "diversidade", "tolerância", "abertura" e "respeito às diferenças", que podem representar uma estratégia visando à identificação do público pela adoção de princípios generalistas.

A categoria Beneficiários faz referência às diferentes palavras que a CIUP emprega para denominar o público beneficiado por seus

Figura 1: Léxicos destacados nas narrativas da CIUP

\begin{tabular}{|c|c|c|c|c|}
\hline \multicolumn{5}{|c|}{ FOLDER: MECENA/DOADOR PARTICULAR } \\
\hline VALORES & BENEFICIÁRIOS & OBJETIVOS/ PRESTAÇÕES & QUALIFICATIVOS CIUP & ENGAJAMENTO \\
\hline diversidade(5) & residentes(8) & diálogo(2) & lugar único(3) & apoie!(3) \\
\hline $\begin{array}{l}\text { respeito às } \\
\text { diferenças }\end{array}$ & jovens(3) & $\begin{array}{l}\text { desenvolvimento de } \\
\text { atividades culturais e } \\
\text { intelectuais(2) }\end{array}$ & qualidade(3) & apoio(3) \\
\hline tolerância & estudantes & viver juntos & aberto a todos & mecenas(2) \\
\hline \multirow[t]{10}{*}{ abertura } & pós-doutorandos & $\begin{array}{c}\text { construção de um } \\
\text { mundo de paz }\end{array}$ & projeto visionário & contribuindo(2) \\
\hline & pesquisadores & $\begin{array}{c}\text { desenvolver a } \\
\text { atratividade da França }\end{array}$ & $\begin{array}{l}\text { patrimônio } \\
\text { arquitetônico }\end{array}$ & doar(2) \\
\hline & artistas & \begin{tabular}{|c|} 
construir uma \\
sociedade mais aberta e \\
tolerante
\end{tabular} & $\begin{array}{c}\text { verda deira exposição } \\
\text { de arquitetura }\end{array}$ & ajudar(2) \\
\hline & intelectuais & crescimento mundial & $\begin{array}{c}\text { lugares privilegiados } \\
\text { de expressão }\end{array}$ & mobilização(2) \\
\hline & & programa de bolsas & & participe \\
\hline & & $\begin{array}{c}\text { valorizar a herança } \\
\text { arquitetônica }\end{array}$ & & meios financeiros \\
\hline & & & & financiamento \\
\hline & & & & associe-se \\
\hline & & & & generosidade \\
\hline & & & & $\begin{array}{c}\text { necessidade de } \\
\text { financiamentos } \\
\text { privados }\end{array}$ \\
\hline
\end{tabular}


projetos, tais como: "residentes", "estudantes", “jovens", "pesquisadores". Ao destacar estas palavras através do recurso negrito, a instituição busca frisar para quem são direcionadas as mensagens veiculadas em seu discurso.

Outra categoria identificada através da análise de conteúdo relaciona-se aos 0bjetivos e às Contribuições à sociedade enunciados pela CIUP. As palavras e expressões destacadas remetem a ações locais, projetos desenvolvidos pela fundação e ainda a seus objetivos, expressos de maneira universal. Considerase 0 uso de expressões majoritariamente universalistas nas narrativas construídas pela CIUP como uma estratégia que visa a atingir ou sensibilizar o público por meio de apelos humanistas de paz e bem comum.

Também foram identificados léxicos que qualificam a fundação e suas atividades, os quais foram agrupados na categoria Qualificativas. A variedade de expressões de qualificação da CIUP demonstra a maneira pela qual ela se autodefine e se mostra à sociedade através de uma narrativa cuidadosamente elaborada. 0 emprego de termos qualificativos induz a uma leitura e interpretação pelo público, refletindo a instituição da forma como ela pretende ser reconhecida: como uma instituição a serviço da diversidade, da atração de talentos etc.

A quinta categoria identificada diz respeito aos termos sublinhados que tem por intuito direto estimular a doação e o engajamento. As expressões são empregadas, em grande parte, no modo imperativo e convidam o leitor a apoiar os projetos e a agir. Em outras palavras, a sensibilização é efetuada mostrando-se a necessidade de financiamento e a importância das doações para a sobrevivência da Fundação e manutenção de seus projetos.

Figura 2: Cadeia lógico-lexical
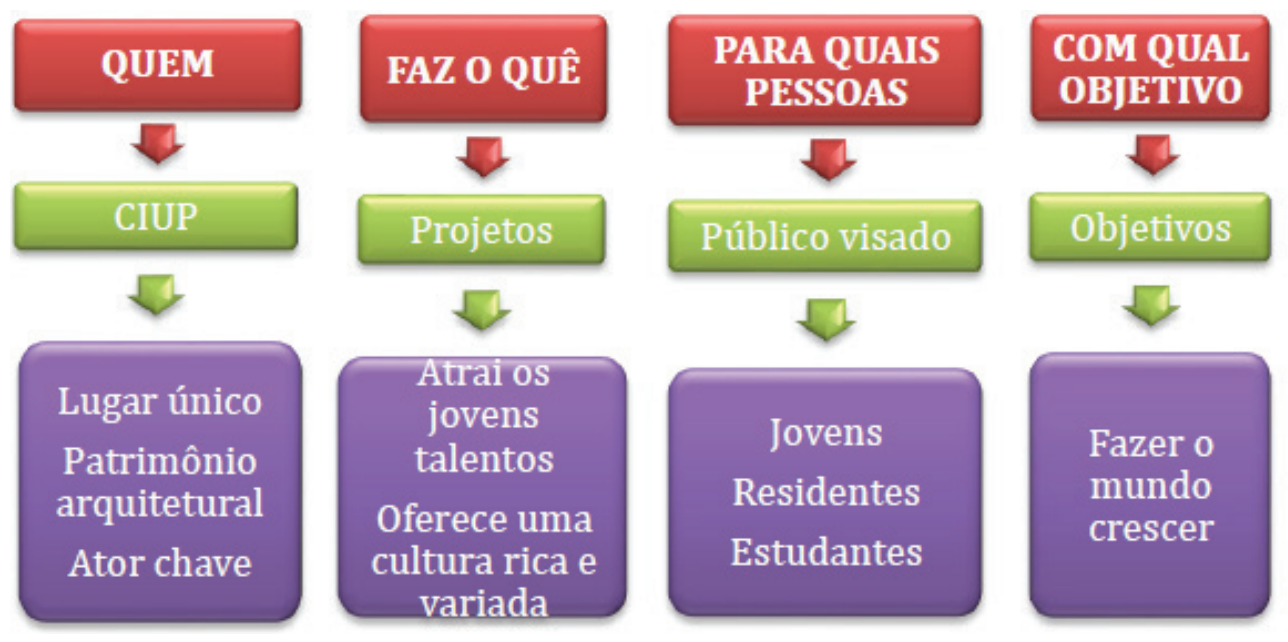

Fonte: elaboração da autora 
De uma maneira geral, a construção lógica e 0 emprego dos léxicos destacados nas narrativas da CIUP podem ser observados através de um encadeamento argumentativo que responde às questões: "Quem faz o quê, para quais pessoas e com qual motivo?".

A fim de exemplificar nossa proposta apresenta-se, na Figura 2, um esquema ilustrativo.

0 esquema proposto demonstra a importância da enunciação editorial como estratégia de destaque dos elementos-chave. Observa-se que os léxicos sublinhados conduzem a leitura da narrativa de forma prescrita. A apreensão das mensagens segue uma lógica prédefinida pela enunciação, expressa pela formatação do texto, por meio de escolhas tipográficas e recursos editoriais.

\section{Estratégia narrativa: escolhas discursivas e argumentativas}

A partir da análise discursiva das narrativas produzidas pela CIUP, e veiculadas em seus folders institucionais, busca-se investigar as estratégias narrativas, as áreas abordadas e a lógica de construção da narrativa organizacional. Nesse sentido, a análise se concentra no nível discursivo e argumentativo da narrativa, em especial na função da narrativa, pois,
[...] a narrativa é sempre um discurso dirigido e esta concepção comunicacional das estratégias discursivas nos obriga a definir a argumentação narrativa como um processo dialógico, como um conjunto de atividades do enunciador para antecipar e conduzir a interpretação do receptor-coenunciator. ${ }^{5}$ (ADAM, 1985, p. 7, tradução nossa).

0 discurso retórico, no sentido proposto por Aristóteles, ou a retórica das narrativas organizacionais, visam a analisar os argumentos e estratégias empregadas para mobilizar os leitores. Da mesma forma, o conceito ideológico do discurso, considerado por Foucault, é também complementar a esta análise, uma vez que tal conceito admite que as narrativas também possuem uma força "legitimadora". Assim, a análise realizada permite observar o discurso ideológico das narrativas, mesmo que não explícito. Conforme evoca Foucault (1969), esta ideologia está sempre presente e é portadora de valores e de simbolismos.

A partir do exame das narrativas construídas pela CIUP observa-se uma lógica narrativa que revela a estratégia desenvolvida pela Fundação. 0s relatos iniciam pela apresentação da CIUP, sua história, seus ideais, bem como os objetivos da campanha. 0 texto gira em torno destes pontos principais, de forma a valorizar os projetos da instituição e destacar a importância do mecenato para sua manutenção.

"le récit est toujours un discours adressé et cette conception communicationnelle des stratégies discursives nous oblige à définir l'argumentation narrative comme un processus dialogique, comme un ensemble d'activités de l'énonciateur pour anticiper et guider l'interprétation du récepteur-coénonciateur". 
Com relação à maneira com que os relatos são apresentados, observa-se uma sistemática narrativa específica composta por quatro etapas: A exposição de si; Valorização do projeto; Estabelecimento do vínculo; Incitação à ação.

\subsection{A exposição de si}

A exposição de si consiste em uma breve apresentação inicial sobre a criação da instituição, sublinhando o papel dos fundadores e os ideais da Fundação. A narrativa começa com a apresentação da organização como sendo um grupo de pessoas unidas pela vontade de fazer o bem. Em seguida, os valores e a missão da CIUP são mostrados como alternativas em resposta às problemáticas mundiais. 0 relato é construído de forma poética e, mais do que princípios organizacionais, demonstra o idealismo da fundação e reflete certos valores que podem ser identificáveis com aqueles dos indivíduos.

Esta etapa remete à exaltação da história da Fundação em que são ressaltadas a força de vontade e a generosidade daqueles que a fundaram, aproximando os valores da CIUP àqueles universais. Nota-se que tais elementos universalistas, e por vezes humanistas, são associados desde 0 início da narrativa à história da instituição.

A história serve, portanto, como ponto de ancoragem para o desenvolvimento da narrativa. Seu papel fundamental ultrapassa a mera descrição de fatos citados na ordem dos acontecimentos. A história é utilizada pela instituição como meio de inspiração para transmitir uma "moral", intrínseca na narrativa. Neste caso particular, a mensagem da CIUP faz referência à importância do mecenato para a acolhida dos jovens em um ambiente multicultural.

A construção e 0 encadeamento argumentativo segue, assim, um raciocínio específico que conduz à moral da história narrada, conforme pode ser observado na Figura 3:

0 sentido da narrativa elaborada pela CIUP remete aos questionamentos evocados por

Figura 3: Esquema argumentativo-narrativo 
Foucault (1969) ao afirmar que a história serve para mostrar, decifrar os feitos humanos a partir dos traços por eles deixados, os quais buscamos revalorizar ou ressignificar. 0 resgate da história bem como a sua reorganização e sua pertinência são aqui retomados graças à narrativa.

\subsection{A valorização do projeto}

Nesta etapa ressalta-se 0 valor agregado à sociedade. São colocadas em evidência as ações conduzidas pela Fundação e as contribuições aos residentes e à comunidade. A construção narrativa nos conduz a compreender o projeto da CIUP como uma missão mundial, em benefício de toda a humanidade, e não apenas dos residentes da Fundação. Os ideais de paz, respeito à diversidade, vida em comunidade, entre outros, são os valores humanitários por meio dos quais a instituição busca sensibilizar o maior número de pessoas.

0 emprego de adjetivos e a ênfase à "qualidade" dos serviços oferecidos e à "excelência" da Fundação simbolizam as escolhas discursivas efetuadas pelo autor durante a construção dos relatos, as quais visam salientar a amplitude da instituição e seu reconhecimento mundial. Da mesma forma, observa-se que a retórica institucional baseia-se no argumento do valor agregado. As prestações à sociedade são exaltadas em termos de contribuição ao sucesso profissional e acadêmico de seus residentes, mas também como meio de desenvolvimento da França.
A narração funciona como uma espécie de lupa que amplia os projetos e ações locais valorizando-os e destacando os benefícios que podem trazer à sociedade. Trata-se de uma estratégia narrativa de autolegitimação em que, por meio de uma construção retórica, os argumentos são ordenados de maneira a convencer o leitor da grandeza das causas promovidas pela CIUP.

Esse tipo de narrativa promove a ideia de que, ao engajar-se à causa promovida pela organização, 0 apoiador estará contribuindo com 0 bem estar da humanidade e para uma sociedade mais justa. 0s relatos são construídos de tal forma que os objetivos e benefícios "micro" sejam percebidos como "macros".

\subsection{Estabelecimento do vínculo}

Consiste na sensibilização e argumentação sobre a importância do apoio dos diferentes públicos para a realização dos projetos institucionais e em benefício de uma causa universal. A narrativa visa tocar, sensibilizar e estimular a reflexão sobre os problemas atuais, mostrando como resolvê-los através do apoio e engajamento para com os objetivos organizacionais.

No caso da Fundação CIUP, busca-se a doação para a continuidade dos projetos. Como forma de alcançar 0 engajamento, isto é, induzir efetivamente à ação, o relato procura estabelecer um vínculo entre a valorização dos projetos e a necessidade do 
aporte financeiro para realizá-los. Nesse sentido, a motivação visando à doação financeira é claramente evidenciada (em detrimento de outras formas de apoio como o voluntariado, por exemplo).

Assim, a estratégia consiste em descrever os objetivos e detalhar os projetos e benefícios ligados a eles, a fim de convencer o público sobre a importância destas ações para, em seguida, evocar a necessidade de apoio à sua concretização. Esta etapa de sensibilização prepara 0 leitor para a fase seguinte em que ele é diretamente interpelado a agir.

\subsection{Incitação à ação}

A última fase identificada remete à mobilização para a ação, observada nas narrativas da CIUP por meio do incentivo direto ao engajamento mecenas - visado em termos monetários e expresso pela doação. Diz respeito à construção narrativa que visa mobilizar diretamente 0 leitor a agir, a engajar-se a uma causa. Para tanto, a CIUP utiliza diferentes argumentos como forma de convencer seus públicos e motivá-los a doar.

Observa-se, especialmente, o uso de verbos de ação no imperativo, conforme explicitado na precedente análise de conteúdo (doe; contribua; participe). A estratégia consiste em apresentar os meios, as alternativas, para que os indivíduos possam engajar-se. Nos relatos da CIUP, os leitores são incitados a doar e a contribuir com a Fundação por meio da apresentação dos benefícios das doações e das principais motivações e as vantagens aos doadores, como os incentivos fiscais. A estratégia discursiva é associada à disponibilização prática das vias pelas quais os indivíduos podem se engajar - inclusão de um formulário de doação, por exemplo.

\section{Considerações finais}

Como forma de responder ao nosso questionamento central, sobre a construção de narrativas que visam motivar para a ação, foram empregadas análises focalizadas no discurso e no conteúdo expresso nos folders da Fundação CIUP. Este procedimento possibilitou a observação de uma lógica narrativa que conduz ao engajamento.

Tais observações confirmam nossa hipótese inicial sobre a produção de narrativas pelas organizações a fim de promover o engajamento dos diferentes públicos para com a missão empresarial. Além disso, dois tipos de estratégias foram identificados: uma estratégia editorial, ligada à tipografia e à formatação dos textos, e uma estratégia narrativa, relacionada à construção discursiva e argumentativa.

Entre os elementos preliminares levantados pela pesquisa observa-se 0 papel central ocupado pelas narrativas nas organizações, como estratégias comunicacionais de potencial mobilizador. A força da narrativa reside em sua função argumentativa, pela qual as histórias são construídas de maneira a estimular 0 leitor 
e produzir nele uma reflexão, uma mudança, mobilizá-lo ou ainda, oferecer-lhe lições de vida.

Destaca-se também o uso da história como um fator chave na construção narrativa, que conduz a uma perspectiva de estudo futura baseada na valorização da história e da memória no contexto organizacional.

\section{Referências}

ADAM, J.-M. Le texte narratif. Paris: Nathan, 1985.

AUSTIN, J. L. How to do Things with words. New York: Oxford University Press, 1962.

BARTHES, R. Théorie du texte.1974. Disponível em: < http://asl.univ-montp3.fr/e41slym/Barthes THEORIE_DU_TEXTE.pdf>.Acesso em: 19 mar. 2012.

BONVILLE, J. L'analyse de contenu des médias. Bruxelles: De Boeck, 2006.

BÜHLER, P.; HABERMACHER, J.-F (Ed.). La

narration. Genève: Labor et Fides, 1988.

CZARNIAWSKA, B. A narrative approach to organization studies. Thousand Oaks, CA: Sage, 1998.

D'ALMEIDA, N. Les promesses de la communication. Paris: Presses Universitaires de France, 2001.

D'ALMEIDA, N. Les organisations entre récits et médias. Canadian Journal of Communication, v. 29, n. 1, p. 25-46, 2004.

D'ALMEIDA, N. Les organisations entre projets et récits. In: BOUZON, A.

(Dir). La communication organisationnelle en débat. Paris: L'Harmattan, 2006.

FAIRCLOUGH, Norman. Discourse and social change. Cambridge: Polity, 1992.

FOUCAULT, M. Larchéologie du savoir. Paris: Gallimard, 1969.
GIROUX, N.; MARROQUIN, L. L'approche narrative des organisations. Revue Française de Gestion, v. 6, n. 159, p. 15-42, 2005.

HERNADI, P. Literary Interpretation and the Rhetoric of the Human Sciences. In: NELSON, J. S.; MEGILL, A.; MCCLOSKEY, D. N. (Ed.). The Rhetoric of the Human Sciences. Wisconsin, MD: University of Wisconsin Press, 1987, p. 263-275.

LYOTARD, J.-F. La condition postmoderne. Paris: Minuit, 1979.

PARSONS, T. The Structure of Social Action. New York: McGraw-Hill, 1937.

PARSONS, T. Action Theory and the Human

Condition. New York: Free Press, 1978.

RICOEUR, P. Du texte à l'action. Paris: Ed. du Seuil, 1986.

SANTOS, L. C. Le récit organisationnel et la promotion de l'engagement. 2012. 115 f. Dissertação (Master em Mention information et communication) -, CELSA, Université Paris-Sorbonne, Paris, 2012.

SCROFERNEKER, C. Trajetórias teórico-conceituais da comunicação organizacional. Revista FAMECOS, Porto Alegre, v. 1, n. 31, p. 47-53, dez. 2006.

SEARLE, J. R. Speech acts. Cambridge: Cambridge University Press, 1969.

SOUCHIER, E. Limage du texte. Cahiers de médiologie, Paris, v.2, n. 6, p. 137-145, 1998.

VON WRIGHT, G. H. Norm and action: a logical enquiry. London: Routledge \& Kegan Paul, 1963. 


\section{Organizational narrative to} promote the engagement

\section{La narrativa organizacional para la promoción del compromiso}

\section{Abstract}

This study aims to analyze the role of organizational narratives for the promotion of engagement. The research is focused on the argumentative function and mobilizing capacity of the narratives produced by organizations and intended for its stakeholders. It adopts interpretive perspective, to understand the organizational narratives, their ability to argumentation and mobilization to action, having as theoretical studies of narratology, the narrative perspective of organizations, the text theory, action theory and the theory of speech acts. As the object of study are analyzed promotional materials developed by the Fondation Cité Internationale Universitaire de Paris (CIUP) intended to gain the support of patronage. To this end, the research is based on methodologies of analysis of discourse and content analysis.

\section{Keywords}

Organizational communication. Narrative.

Organizations.

\section{Resumen}

Por medio de este estudio se pretende analizar la promoción del compromiso. La investigación se ha centrado en la función argumentativa y la capacidad de movilización de las narrativas a sus accionistas. Se adopta una perspectiva interpretativa dirigida a comprender las narrativas organizacionales, su capacidad de argumentación y movilización a la acción, teniendo como estudios de fundamentación teórica la narratología, la perspectiva de las organizaciones, teoría del texto, la teoría de la acción y la teoría de los actos del lenguaje. Como objeto de estudio son analizados el material promocional desarrollado por la Fondation Cité Internationale Universitaire de Paris (CIUP) destinado a obtener el apoyo de mecenas. Con este fin, la investigación se basa en metodologías de análisis del discurso y análisis de contenido.

\section{Palabras clave}

Comunicación organizacional. Narrativa Organizaciones. el papel de las narrativas organizacionales para producidas por organizaciones y de direccionadas 


\section{Expediente}

A revista E-Compós é a publicação científica em formato eletrônico da Associação Nacional dos Programas de Pós-Graduação em Comunicação (Compós). Lançada em 2004, tem como principal finalidade difundir a produção acadêmica de pesquisadores da área de Comunicação, inseridos em instituições do Brasil e do exterior.

\section{E-COMPÓS I www.e-compos.org.br I E-ISSN 1808-2599}

Revista da Associação Nacional dos Programas

de Pós-Graduação em Comunicacão.

Brasília, v.17, n.1, jan./abri. 2014.

A identificação das edições, a partir de 2008

passa a ser volume anual com três números.

\section{CONSELHO EDITORIAL}

Afonso Albuquerque, Universidade Federal Fluminense, Brasil Alberto Carlos Augusto Klein, Universidade Estadual de Londrina, Brasil Alex Fernando Teixeira Primo, Universidade Federal do Rio Grande do Sul, Brasil Ana Carolina Damboriarena Escosteguy, Pontifícia Universidade Católica do Rio Grande do Sul, Brasi

Ana Gruszynski, Universidade Federal do Rio Grande do Sul, Brasil Ana Silvia Lopes Davi Médola, Universidade Estadual Paulista, Brasil André Luiz Martins Lemos, Universidade Federal da Bahia, Brasi Ângela Freire Prysthon, Universidade Federal de Pernambuco, Brasil Antônio Fausto Neto, Universidade do Vale do Rio dos Sinos, Brasil Antonio Carlos Hohlfeldt, Pontifícia Universidade Católica do Rio Grande do Sul, Brasil Antonio Roberto Chiachiri Filho, Faculdade Cásper Líbero, Brasi Arlindo Ribeiro Machado, Universidade de São Paulo, Brasil Arthur Autran Franco de Sá Neto, Universidade Federal de São Carlos, Brasi Benjamim Picado, Universidade Federal Fluminense, Brasil César Geraldo Guimarães, Universidade Federal de Minas Gerais, Brasil Cristiane Freitas Gutfreind, Pontifícia Universidade Católica do Rio Grande do Sul, Brasil Denilson Lopes, Universidade Federal do Rio de Janeiro, Brasil Denize Correa Araujo, Universidade Tuiuti do Paraná, Brasi Edilson Cazeloto, Universidade Paulista , Brasil

Eduardo Vicente, Universidade de São Paulo, Brasil Eneus Trindade, Universidade de São Paulo, Brasil Erick Felinto de Oliveira, Universidade do Estado do Rio de Janeiro, Brasi Gelson Santana, Universidade Anhembi/Morumbi, Brasi Gilson Vieira Monteiro, Universidade Federal do Amazonas, Brasil Gislene da Silva, Universidade Federal de Santa Catarina, Brasil Guillermo Orozco Gómez, Universidad de Guadalajara Gustavo Daudt Fischer, Universidade do Vale do Rio dos Sinos, Brasil Hector Ospina, Universidad de Manizales, Colômbia Herom Vargas, Universidade Municipal de São Caetano do Sul, Brasil Ieda Tucherman, Universidade Federal do Rio de Janeiro, Brasil Inês Vitorino, Universidade Federal do Ceará, Brasil Janice Caiafa, Universidade Federal do Rio de Janeiro, Brasil Jay David Bolter, Georgia Institute of Technology Jeder Silveira Janotti Junior, Universidade Federal de Pernambuco, Brasi João Freire Filho, Universidade Federal do Rio de Janeiro, Brasil Florence Dravet, Universidade Católica de Brasília, Brasil John DH Downing, University of Texas at Austin, Estados Unidos

José Afonso da Silva Junior, Universidade Federal de Pernambuco, Brasil José Carlos Rodrigues, Pontifícia Universidade Católica do Rio de Janeiro, Brasil José Luiz Aidar Prado, Pontifícia Universidade Católica de São Paulo, Brasil José Luiz Warren Jardim Gomes Braga, Universidade do Vale do Rio dos Sinos, Brasil Juremir Machado da Silva, Pontifícia Universidade Católica do Rio Grande do Sul, Brasil Laan Mendes Barros, Universidade Metodista de São Paulo, Brasil Lance Strate, Fordham University, USA, Estados Unidos Lorraine Leu, University of Bristol, Grã-Bretanha Lucia Leão, Pontifícia Universidade Católica de São Paulo, Brasil Luciana Panke, Universidade Federal do Paraná, Brasil Luiz Claudio Martino, Universidade de Brasília, Brasil Malena Segura Contrera, Universidade Paulista, Brasil Márcio de Vasconcellos Serelle, Pontifícia Universidade Católica de Minas Gerais, Brasil Maria Aparecida Baccega, Universidade de São Paulo e Escola Superior de Propaganda e Marketing, Brasil Maria das Graças Pinto Coelho, Universidade Federal do Rio Grande do Norte, Brasil Maria Immacolata Vassallo de Lopes, Universidade de São Paulo, Brasil Maria Luiza Martins de Mendonça, Universidade Federal de Goiás, Brasil Mauro de Souza Ventura, Universidade Estadual Paulista, Brasil Mauro Pereira Porto, Tulane University, Estados Unidos Nilda Aparecida Jacks, Universidade Federal do Rio Grande do Sul, Brasil Paulo Roberto Gibaldi Vaz, Universidade Federal do Rio de Janeiro, Brasil Potiguara Mendes Silveira Jr, Universidade Federal de Juiz de Fora, Brasil Renato Cordeiro Gomes, Pontifícia Universidade Católica do Rio de Janeiro, Brasil Robert K Logan, University of Toronto, Canadá

Ronaldo George Helal, Universidade do Estado do Rio de Janeiro, Brasil Rosana de Lima Soares, Universidade de São Paulo, Brasi Rose Melo Rocha, Escola Superior de Propaganda e Marketing, Brasil Rossana Reguillo, Instituto de Estudos Superiores do Ocidente, Mexico Rousiley Celi Moreira Maia, Universidade Federal de Minas Gerais, Brasi Sebastião Carlos de Morais Squirra, Universidade Metodista de São Paulo, Brasil Sebastião Guilherme Albano da Costa, Universidade Federal do Rio Grande do Norte, Brasil

Simone Maria Andrade Pereira de Sá, Universidade Federal Fluminense, Brasi Tiago Quiroga Fausto Neto, Universidade de Brasilia, Brasil Suzete Venturelli, Universidade de Brasília, Brasil Valerio Fuenzalida Fernández, Puc-Chile, Chile Veneza Mayora Ronsini, Universidade Federal de Santa Maria, Brasil Vera Regina Veiga França, Universidade Federal de Minas Gerais, Brasil

\section{COMISSÃO EDITORIAL}

Cristiane Freitas Gutfreind I Pontifícia Universidade Católica do Rio Grande do Sul, Brasil Irene Machado I Universidade de São Paulo, Brasil

Jorge Cardoso Filho I Universidade Federal do Reconcavo da Bahia, Brasil / Universidade Federal da Bahia, Brasil

CONSULTORES AD HOC

Adriana Amaral, Universidade do Vale do Rio dos Sinos, Brasil

Alexandre Rocha da Silva, Universidade Federal do Rio Grande do Sul, Brasi Arthur Ituassu, Pontifícia Universidade Católica do Rio de Janeiro, Brasil Bruno Souza Leal, Universidade Federal de Minas Gerais, Brasil Elizabeth Bastos Duarte, Universidade Federal de Santa Maria, Brasil Francisco Paulo Jamil Marques, Universidade Federal do Ceará, Brasil Maurício Lissovsky, Universidade Federal do Rio de Janeiro, Brasil Suzana Kilpp, Universidade do Vale do Rio dos Sinos, Brasil Vander Casaqui, Escola Superior de Propaganda e Marketing, Brasil

EDIÇÃO DE TEXTO E RESUMOS I Susane Barros SECRETÁRIA EXECUTIVA I Helena Stigger EDITORAÇÃo ELETRÔNICA I Roka Estúdio
COMPÓS I www.compos.org.br

Associação Nacional dos Programas de Pós-Graduação em Comunicação

Presidente

Eduardo Morettin

Universidade de São Paulo, Brasil

eduardomorettin@usp.br

Vice-presidente

Inês Vitorino

Universidade Federal do Ceará, Brasil

ines@ufc.br

Secretária-Geral

Gislene da Silva

Universidade Federal de Santa Catarina, Brasil

gislenedasilva@gmail.com 